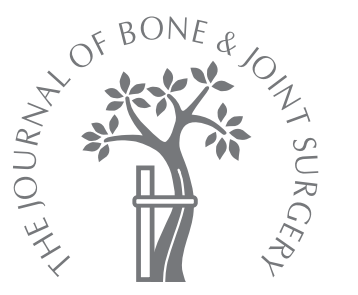

- CASE REPORT

\title{
Spontaneous compartment syndrome of the foot
}

\author{
C. E. Hill, \\ C. S. Modi, \\ N. Baraza, \\ M. S. Mosleh- \\ Shirazi, \\ V. Dhukaram \\ From University \\ Hospital of Coventry \\ and Warwick, \\ Coventry, United \\ Kingdom
}

C. E. Hill, MRCS, BMBS,

BMedSci (Hons), Specialty

Trainee Yr 2 in Trauma and

Orthopaedic Surgery

ㄷ. C. S. Modi, MRCS, DipSEM,

MSc, Registrar in Trauma and

Orthopaedic Surgery

N. Baraza, MBChB, MRCS,

Registrar in Trauma and

Orthopaedic Surgery

M. S. Mosleh-Shirazi,

MBChB, Core Trainee Yr 1 in

Trauma and Orthopaedic

Surgery

V. Dhukaram, FRCS(Orth),

Consultant Ankle and Foot

Surgeon

University Hospital of Coventry and Warwick, Clifford Bridge

Road, Coventry CV2 2DX, UK.

Correspondence should be sent to $\mathrm{Mr} \mathrm{C}$. E. Hill; e-mail:

chill295@doctors.net.u

(C)2011 British Editorial Society

of Bone and Joint Surgery

doi:10.1302/0301-620X.93B9.

$27377 \$ 2.00$

$J$ Bone Joint Surg Br

2011;93-B:1282-4.

Received 14 April 2011;

Accepted after revision 24 May

2011

\begin{abstract}
Compartment syndrome of the foot is usually associated with trauma, and if untreated may result in deformity and loss of function. We report a case of spontaneous compartment syndrome of the foot presenting with severe unremitting pain. The diagnosis was supported by measurements of compartment pressures and the symptoms resolved after surgical decompression. Spontaneous compartment syndrome in the leg has been described in a small number of cases, but there has been no previous report involving the foot. We believe that this case highlights the importance of suspecting a spontaneous compartment syndrome of the foot if the appropriate symptoms are present but there is no clear cause. We also believe that compartment pressure measurement assists in the decision to undertake surgical decompression.
\end{abstract}

Compartment syndrome is characterised by an increase in interstitial pressure within an osteofascial compartment, leading to a reduction in tissue perfusion and ischaemia. ${ }^{1}$ Late diagnosis or neglect can be disastrous, and potential sequelae include myonecrosis, contractures, functional impairment, amputation, renal failure and even death. It is usually associated with musculoskeletal injuries, burns, or complications of surgery. ${ }^{2}$ Rarer causes include intense muscular activity in athletes, ${ }^{3}$ primary and secondary myopathies, ${ }^{4,5}$ statin consumption, ${ }^{6,7}$ ischaemic pathologies, ${ }^{4}$ metabolic disorders such as diabetes mellitus ${ }^{8,9}$ and hyperaldosteronism, ${ }^{10}$ intravenous drug abuse ${ }^{11,12}$ and alcohol consumption. ${ }^{10}$ We present a case of a spontaneous compartment syndrome of the foot with no obvious precipitating cause and highlight important features that might be helpful in the management of future cases.

\section{Case report}

A 38-year-old woman presented in the early hours of the morning with a four-hour history of severe unremitting pain in her left leg and foot unresponsive to simple analgesics. There was no history of any precipitating cause. Her past medical history included two previous episodes of compartment syndrome in the right leg, the first occurring spontaneously in 2004 and the second five years later following a total knee replacement (TKR), both of which resolved after fasciotomy. The TKR was performed for severe early-onset rheumatoid arthritis which had failed to improve with medical management or arthroscopic synovectomy.

On examination the left leg and foot were swollen and tight, with slight bruising but no erythema or warmth. Passive movement of the toes produced a marked increase in pain in the foot and calf. There was no neurovascular deficit and radiographs showed no bony abnormality. Her right leg was asymptomatic, with soft compartments and well-preserved pain-free movement. Blood tests, including biochemistry, liver function, full blood count, bone profile, clotting profile and blood films, were normal. A clinical diagnosis of spontaneous compartment syndrome affecting the leg and foot was made and she was taken to the operating theatre for urgent surgical decompression.

Under general anaesthesia she was placed supine and her blood pressure recorded as 112/60 mmHg. Compartment pressures within the left leg and foot were measured using an arterial line transducer with a continuous column of fluid attached to a venous cannula. The transducer was positioned at the appropriate height and zeroed before each measurement. Each reading was repeated three times and a mean measurement calculated. The pressures were $36 \mathrm{mmHg}$ in the anterior compartment, $30 \mathrm{mmHg}$ in the lateral, $31 \mathrm{mmHg}$ in the superficial posterior and $27 \mathrm{mmHg}$ in the deep posterior. The pressures in the foot were $27 \mathrm{mmHg}$ in the lateral compartment, $40 \mathrm{mmHg}$ in the medial and $85 \mathrm{mmHg}$ in the calcaneal. 
The time to decompression was five hours from the onset of symptoms. Fasciotomies of the leg were performed through two incisions to decompress the anterior, lateral and posterior compartments. In the anterior and lateral compartments the muscle was found to be swollen and bulging but there was no evidence of ischaemia or necrosis. The muscles in the posterior compartments were normal. The foot was decompressed through three incisions. The first, beginning at the medial side of the calcaneum, $4 \mathrm{~cm}$ from the posterior aspect of the heel and $3 \mathrm{~cm}$ superior to the plantar surface, was extended distally for $6 \mathrm{~cm}$, parallel to the plantar surface. Following this medial compartment fasciotomy the abductor hallucis was reflected superiorly to allow splitting of the intermuscular septum and access to, and decompression of, the calcaneal compartment. The superficial compartment was identified and opened longitudinally. Inferior retraction of the flexor digitorum brevis allowed exposure of the lateral compartment, which was duly decompressed. Two further dorsal incisions were made, medial to the second metatarsal and lateral to the fourth metatarsal, in order to decompress the interosseous compartments while preserving an adequate skin bridge. Biopsies of muscle and deep fascia were sent for histological examination. Post-operatively she was much more comfortable and able to actively move her toes and ankle with minimal pain, and there was no neurovascular deficit. All the wounds were closed several days later except for the medial incision which was covered with a negative pressure dressing until the swelling had reduced and the skin edges could be approximated without tension. Five days after this the wound was infected with Staphylococcus aureus. Following debridement and antibiotic therapy it was left to heal by secondary intention.

The biopsies of muscle and deep fascia taken at operation failed to show any obvious cause for the compartment syndrome. They demonstrated inflamed and partly nonviable skeletal muscle and deep fascia, with no microorganisms seen on diastase-predigested periodic acid-Schiff or Gram stains.

\section{Discussion}

Compartment syndrome of the foot is rare and prior to the late 1980s was largely unrecognised in the literature. ${ }^{13,14}$ Myerson $^{15}$ found that the overall incidence of compartment syndrome of the foot was $41 \%$ when associated with crush injuries and $17 \%$ with calcaneal fractures. Later studies found that approximately $10 \%$ of patients with a calcaneal fracture develop compartment syndrome of the foot. ${ }^{16,17}$

Spontaneous compartment syndrome of the foot has not previously been reported, although a small number of cases have been described in the leg. ${ }^{11,18-20}$ The majority of these revealed an association with diabetes, with two conflicting views on pathogenesis. One suggests that metabolic disturbances cause osmotic accumulation of fluid in muscle, leading to increased pressure, necrosis and ischaemia. The other view is that microvascular blockage leads to spontaneous muscle infarction and a subsequent rise in compartmental pressure. $^{6,11,21}$ In our patient, however, there was no evidence of a relationship with diabetes or any other known cause. She did, however, suffer from rheumatoid arthritis and although this was quiescent and did not require regular medication, it may have contributed to an inflammatory aetiology.

It is currently accepted that there are nine compartments of the foot that can be involved in a compartment syndrome. Three run the entire length of the foot: the medial (flexor hallucis, abductor hallucis), lateral (abductor digiti quinti, flexor digiti minimi) and superficial (flexor digitorum brevis, the lumbricals and flexor digitorum longus). Five are contained within the forefoot: the adductor and four interossei. The calcaneal compartment is confined to the hindfoot and contains flexor digitorum brevis, quadratus plantae and adductor hallucis, and many neurovascular structures. However, it communicates with the deep posterior compartment of the leg, and injuries such as calcaneal fractures, tibial fractures and crush injuries to either compartment have resulted in combined compartment syndromes. Pressures should be checked routinely in both these compartments whenever there is suspected compartment syndrome of the leg. ${ }^{22}$ The discovery of this communication, along with confirmation of the nine compartments of the foot, was demonstrated using cadaveric dye injection studies by Manoli and Weber, ${ }^{23}$ who reported that neurovascular structures, including the posterior tibial nerve and vessels, which traverse the calcaneal compartment carry the greatest risk of long-term deficit if they are not decompressed.

The choice of fasciotomy approach is governed by surgeon preference, other planned procedures and the presence of any pre-existing soft-tissue injury. We advocate the approach recommended by Myerson, ${ }^{24}$ and Myerson and Manoli ${ }^{16}$ which combinds two dorsal and one medial plantar incision as described above. This proved successful in this case, resulting in satisfactory decompression of all the compartments and a good clinical outcome.

We believe that this case highlights the importance of suspecting a spontaneous compartment syndrome of the foot if the typical symptoms are present, even if there is no clear cause. We also believe that the measurement of the compartment pressures helped us to undertake surgical decompression correctly and avoid a potentially poor outcome.

No benefits have been received or will be received from a commercial party related directly or indirectly to the subject of this article.

\section{References}

1. Adornato MC, Glawson S, Sadoff RS. Spontaneous compartment syndrome in a diabetic patient: a case report. J Oral Maxillofac Surg 2000;58:1327-1329.

2. Chautems RC, Irmay F, Magnin M, Morel P, Hoffmeyer P. Spontaneous anterior and lateral tibial compartment syndrome in a type I diabetic patient: case report. $J$ Trauma 1997;43:140-141

3. OIson SA, Glasgow RR. Acute compartment syndrome in lower extremity musculoskeletal trauma. J Am Acad Orthop Surg 2005;13:436-444. 
4. Mendieta JM, Rubio J, Elías M, Company R. Bilateral compartment syndrome after surgical perfusion for chronic ischemia of the lower extremities. Rev Esp Anestesiol Reanim 2004:51:155-157.

5. Omar MA, Wilson JP, Cox TS. Rhabdomyolysis and HMG-CoA reductase inhibitors. Ann Pharmacother 2001;35:1096-1107.

6. Pamoukian VN, Rubino F, Iraci JC. Review and case report of idiopathic lower extremity compartment syndrome and its treatment in diabetic patients. Diabetes Metab 2000;26:489-492.

7. Parvizi J, Shaughnessy WJ. Compartment syndrome in a patient with familial rhabdomyolysis: a case report. J Bone Joint Surg [Am]2002;84-A:2046-2049.

8. Raso AM, Visentin I, Zan S, et al. Vascular pathology of surgical interest in drug addicts. Minerva Cardioangio/ 2002;48:287-296.

9. Sen S, Chini EN, Brown MJ. Complications after unintentional intra-arterial injection of drugs: risks, outcomes, and management strategies. Mayo Clin Proc 2005;80:783-795.

10. Flamini S, Zoccali C, Persi E, Calvisi V. Spontaneous compartment syndrome in a patient with diabetes and statin administration: a case report. J Orthop Traumatol 2008;9:101-103.

11. Jose RM, Viswanathan $\mathbf{N}$, Aldlyami $\mathbf{E}$, et al. A spontaneous compartment syndrome in a patient with diabetes. J Bone Joint Surg [Br] 2004;86-B:1068-1070.

12. Matsen FA 3rd, Winquist RA, Krugmire RB Jr. Diagnosis and management of compartmental syndromes. J Bone Joint Surg [Am] 1980;62-A:286-291.

13. Myerson MS. Experimental decompression of the fascial compartments of the foot: the basis for fasciotomy in acute compartment syndromes. Foot Ankle 1988;8:308-314.
14. Myerson MS. Acute compartment syndromes of the foot. Bull Hosp Jt Dis Orthop Inst 1987;47:251-261.

15. Myerson MS. Management of compartment syndromes of the foot. Clin Orthop 1991;271:239-248.

16. Myerson M, Manoli A. Compartment syndromes of the foot after calcaneal fractures. Clin Orthop 1993;290:142-150.

17. Andermahr J, Helling HJ, Tsironis K, Rehm KE, Koebke J. Compartment syndrome of the foot. Clin Anat 2001;14:184-189.

18. Rosenfield AL, Bartal E. Bilateral spontaneous lateral compartment syndrome in the legs of a patient who received a kidney and heart transplant: a case report. J Bone Joint Surg [Am] 1992;74-A:775-776.

19. Khan SK, Thati S, Gozzard C. Spontaneous thigh compartment syndrome. West J Emerg Med 2011;12:134-138.

20. Mahdi H, Gough S, Gill KK, Mahon B. Acute spontaneous compartment syndrome in recent onset type 1 diabetes. Emerg Med J 2007;24:507-508.

21. Smith AL, Laing PW. Spontaneous compartment syndrome in Type 1 diabetes mellitus. Diabet Med 1999;16:168-169.

22. Fulkerson E, Afshin R, Nirmal T. Review: acute compartment syndrome of the foot. Foot Ankle Int 2003;24:180-187.

23. Manoli A 2nd, Weber TG. Fasciotomy of the foot: an anatomical study with special reference to release of the calcaneal compartment. Foot Ankle 1990;10:267-275.

24. Myerson M. Diagnosis and treatment of compartment syndrome of the foot. Orthopedics 1990;13:711-717. 